\title{
Amorphous Phosphate Crystals Measurement
}

National Cancer Institute

\section{Source}

National Cancer Institute. Amorphous Phosphate Crystals Measurement. NCI

Thesaurus. Code C92243.

The determination of the amount of amorphous phosphate crystals present in a sample. 